\title{
Accelerated Reduction of Chlorinated Nitroaromatic Antibiotic Chloramphenicol by Biocathode
}

Bin Liang, ${ }^{\dagger \dagger}$ Hao-Yi Cheng, ${ }^{\dagger, \dagger}$ De-Yong Kong, ${ }^{\dagger}$ Shu-Hong Gao, ${ }^{\dagger}$ Fei Sun, ${ }^{\ddagger}$ Dan Cui, ${ }^{\dagger}$ Fan-Ying Kong, ${ }^{\dagger}$ Ai-Juan Zhou, ${ }^{\dagger}$ Wen-Zong Liu, ${ }^{\dagger, \S}$ Nan-Qi Ren, ${ }^{\dagger}$ Wei-Min Wu, ${ }^{\dagger, \|}$ Ai-Jie Wang, ${ }^{\dagger, \S, *}$ and Duu-Jong Lee ${ }^{\dagger, \mathcal{I}^{\prime}, *}$

${ }^{\dagger}$ State Key Laboratory of Urban Water Resource and Environment, School of Municipal and Environmental Engineering, Harbin Institute of Technology, Harbin, 150090, P. R. China

${ }^{\ddagger}$ School of Environmental and Civil Engineering, Jiangnan University, Wuxi, Jiangsu Province, 214122, P. R. China

${ }^{\S}$ Research Center for Eco-Environmental Sciences, Chinese Academy of Sciences, Beijing, 100085, P. R. China

"Department of Civil \& Environmental Engineering, and Center for Sustainable Development \& Global Competitiveness, Stanford University, Stanford, California 94305-4020, United States

${ }^{\perp}$ Department of Chemical Engineering, National Taiwan University, Taipei 10617, Taiwan

\section{Supporting Information}

ABSTRACT: Chlorinated nitroaromatic antibiotic chloramphenicol (CAP) is a priority pollutant in wastewaters. A fedbatch bioelectrochemical system (BES) with biocathode with applied voltage of $0.5 \mathrm{~V}$ (served as extracellular electron donor) and glucose as intracellular electron donor was applied to reduce CAP to amine product $(\mathrm{AMCl} 2)$. The biocathode BES converted $87.1 \pm 4.2 \%$ of $32 \mathrm{mg} / \mathrm{L}$ CAP in $4 \mathrm{~h}$, and the removal efficiency reached $96.0 \pm 0.9 \%$ within $24 \mathrm{~h}$. Conversely, the removal efficiency of CAP in BES with an abiotic cathode was only $73.0 \pm 3.2 \%$ after $24 \mathrm{~h}$. When the biocathode was disconnected (no electrochemical reaction but in the presence of microbial activities), the CAP removal rate

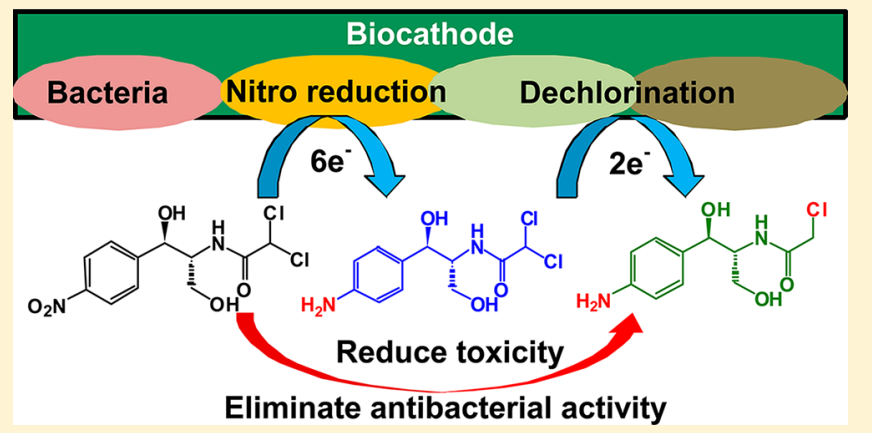
was dropped to $62.0 \%$ of that with biocathode BES. Acetylation of one hydroxyl of CAP was noted exclusive in the biocatalyzed process, while toxic intermediates, hydroxylamino (HOAM), and nitroso (NO), from CAP reduction were observed only in the abiotic cathode BES. Electrochemical hydrodechlorination and dehalogenase were responsible for dechlorination of $\mathrm{AMCl} 2$ to $\mathrm{AMCl}$ in abiotic and microbial cathode BES, respectively. The cyclic voltammetry (CV) highlighted higher peak currents and lower overpotentials for CAP reduction at the biocathode compared with abiotic cathode. With the biocathode BES, antibacterial activity of CAP was completely removed and nitro group reduction combined with dechlorination reaction enhanced detoxication efficiency of CAP. The CAP cathodic transformation pathway was proposed based on intermediates analysis. Bacterial community analysis indicated that the dominate bacteria on the biocathode were belonging to $\alpha, \beta$, and $\gamma$-Proteobacteria. The biocathode BES could serve as a potential treatment process for CAP-containing wastewater.

\section{INTRODUCTION}

After application of antibiotic for more than sixty years, the presence of antibiotic in environment, particularly in the receiving waters, poses adverse ramifications for human health by yielding emerging antibiotic resistant bacteria and antibiotic resistant genes. ${ }^{1,2}$ The chlorinated nitroaromatic antibiotic chloramphenicol (CAP) (2,2-dichloro-N-[(1R,2R)-2-hydroxy1-(hydroxymethyl)-2-(4-nitrophenyl) ethyl] acetamide) was introduced into clinical practice in 1949 and also the first synthetic antibiotic to be applied at large scale, ${ }^{3}$ serving as an effective bacteriostatic antimicrobial to many Gram-positive and Gram-negative bacteria, including most anaerobic organisms. However, owing to the fatal toxicity of CAP to aplastic anemia and the potential carcinogenicity and genotoxicity of CAP to humans, ${ }^{3,4}$ the U.S. Food and Drug Administration banned its use on food-producing animals. Although the CAP is no longer a first-line drug in the U.S. and other developed nations, it is still used in low-income countries owing to its low production cost and wide availability. In Asian countries including China, CAP concentration ranging $26-2430 \mathrm{ng} / \mathrm{L}$ in the influent and 3-1050 ng/L in the effluent of sewage treatment plants were noted. $^{5-12}$ In specific studies the CAP concentration in sewage (Guiyang, China) was observed as high as $47.4 \mu \mathrm{g} / \mathrm{L} .{ }^{13}$ Upon $\mathrm{CAP}$ exposure the CAP resistant bacteria/genes were found in numerous water streams. ${ }^{14-16}$

The nitro group of CAP is the essential functional group determining its antibiotic properties. ${ }^{17,18}$ The CAP toxicity can

Received: February 28, 2013

Revised: April 17, 2013

Accepted: April 22, 2013

Published: April 22, 2013 
be effectively mitigated by anaerobic transformation of the nitroaromatics to aromatic amines, with the latter being less toxic and considerably easier to be mineralized than the former. ${ }^{19-21}$ Dehalogenation generally makes halogenated compounds less toxic and more readily biodegradable. ${ }^{22}$ Physical-chemical methods such as photocatalytic degradation, ${ }^{23}$ Fenton process, ${ }^{24}$ zerovalent bimetallic nanoparticles ${ }^{25}$ and microwave radiation ${ }^{26}$ were proposed for CAP removal at the expense of high energy and chemical costs. The bioelectrochemical system (BES) with biocatalyzed cathodic reduction is an emerging technology that could reductively degrade various pollutants including chloroethenes, ${ }^{27,28}$ chlorophenols, ${ }^{29,30}$ azo dyes, ${ }^{31,32} \mathrm{Cr}(\mathrm{VI}),{ }^{33} \mathrm{U}(\mathrm{VI}),{ }^{34}$ and perchlorate $^{35}$ in waters. Additionally, the BES was demonstrated effective on converting nitroaromatic nitrobenzene to aniline. ${ }^{19,36-38}$ Although the bioanode BES was claimed to be capable of degrading antibiotic such as sulfonamides, ceftriaxone, and penicillin, ${ }^{39-41}$ no report has been published on the feasibility of using biocathode BES technology for removing antibacterial activity and enhancing biodegradability of CAP.

This study aims at revealing the feasibility of cathodic reduction of CAP with $\mathrm{BES}$ and unveiling the reaction pathways. We demonstrated that the CAP removal efficiency in the BES with biocathode was significantly enhanced and $\mathrm{CAP}$ reduction rate accelerated using $\mathrm{BES}$ with an abiotic cathode as a control. The results have proven the effectiveness of removal of an antibiotic using biocathode BES.

\section{MATERIALS AND METHODS}

Reactor Setup. Same sized, dual chamber BES reactors made of polycarbonate were constructed by assembling two equal-size Lexan plates $\left(7 \times 7 \times 4 \mathrm{~cm}^{3}\right)$ with a cylindrical cavity ( $5 \mathrm{~cm}$ in diameter, $4 \mathrm{~cm}$ in length) (Supporting Information (SI) Figure S1). One set reactor was started as biocathode BES with microbial inoculation while another set was started as abiotic cathode BES without inoculation. For BES construction, the two plates were bolted together between two equal-size Lexan plates $\left(7 \times 7 \times 1 \mathrm{~cm}^{3}\right)$ and separated by a cation exchange membrane (Ultrex CMI-7000, Membranes International, U.S.). The working volume of each chamber was $85 \mathrm{~mL}$. A graphite fiber brush $(4 \mathrm{~cm}$ in diameter and $30 \mathrm{~mm}$ in length, TOHO TENAX Co., Ltd., Japan) was used as anode. For the $\mathrm{CAP}$ reduction tests, carbon cloth $(5 \mathrm{~cm}$ in diameter, nonwet proof, YB-20, YiBang Technology Co., Ltd., China) was used as the cathode, which was pretreated by immersing them in $1 \mathrm{M}$ hydrochloric acid for $24 \mathrm{~h}$ then immersed in deionized water for another $24 \mathrm{~h}$. Titanium wire $(1 \mathrm{~mm}$ in diameter, Baoji LiXing Titanium Group Co., Ltd., China) was connected onto the cathode as current collector. A high-precision resistor (10 $\Omega$ ) with the power in series was employed for the connection. External power source $(0.5 \mathrm{~V})$ was applied to test CAP reduction during abiotic cathode and biocathode BES operation unless otherwise mentioned. Saturated calomel reference electrode (SCE, $0.247 \mathrm{~V}$ vs standard hydrogen electrode (SHE), model-217, Shanghai Precise. Sci. Instru. Co., Ltd., China) was inserted into the cathode chamber to measure the cathode potential. All of the potentials reported herein were against SHE. When the additional power source and the resistor were disconnected the BES was operated as opened biocathode mode. The tests with opened biocathode BES lasted for $120 \mathrm{~h}$, hence should have minimal effects on the microbial communities in the biofilms.
Microbial Inoculum and BES Tests. Microbial consortium used as the inoculum of the biocathode was preenriched using activated sludge obtained from Taiping wastewater treatment plant, Harbin, China. Sludge (about 10 g dry weight) was mixed with $200 \mathrm{~mL}$ anaerobic medium which was prepared by boiling and purged with $\mathrm{N}_{2}$ gas (99.9\% purity) for $15 \mathrm{~min}$. The medium consisted of CAP $(32 \mathrm{mg} / \mathrm{L})$, glucose $(500 \mathrm{mg} / \mathrm{L})$, and the nutrient medium previously described. ${ }^{36}$ The mixed culture was incubated in a rotary shaker at $160 \mathrm{rpm}$ and $25{ }^{\circ} \mathrm{C}$ for one week, and then was transferred to another fresh medium $(180 \mathrm{~mL})$ at $10 \%$ dilution once a week. This procedure was repeated four times. The CAP-removal efficiency of the enriched consortium was monitored by determine CAP concentration using HPLC described below. Finally, the enriched consortium, or CAP-reducing consortium, was capable of converting CAP to amine product by $88.0 \pm$ $4.7 \%$ in $72 \mathrm{~h}$.

To start up the biocathode BES, the cathode chamber was filled with a mixture of the CAP-reducing consortium and catholyte at $1: 3(\mathrm{v} / \mathrm{v})$ and incubated for 4 days with the applied voltage of $0.5 \mathrm{~V}$. Subsequently, the cathode liquid content was discharged and the cathode chamber was replenished with a fresh mixture. This procedure was repeated for five times to achieve the development of biofilm on the cathode. Two BES reactors with well-developed biocathode were operated using CAP as substrate for five batch cycles to collect data of biocathode mode. Subsequently, these two reactors were switched to opened circuit and disconnection of additional power source $(0.5 \mathrm{~V})$ for further test as opened biocathode mode. Under this condition, the microbial population of biocathode conducted bioreduction of CAP with glucose as electron donor but no electron flowed from anode to the biocathode. Other two BES reactors with abiotic cathode, as well as the control experiment (no current and microbes) were operated for three cycles. The catholyte was prepared anaerobically by aerating $\mathrm{N}_{2}$ gas and filtered via a $0.22 \mu \mathrm{m}$ filter during all the experiments. To maintain sufficient levels of electron donor acetate in the anodic chamber, anolyte was replenished when the catholyte was refilled. All tests were conducted at room temperature $\left(26 \pm 2{ }^{\circ} \mathrm{C}\right)$.

Chemicals and Analytical Methods. Chloramphenicol (>98\% purity) and HPLC grade methanol were purchased from Sigma-Aldrich. Ethyl acetate and chloroform used were of analytical grade.

Purification of major products during CAP transformation was conducted using thin layer chromatography (TLC) technology. The effluent $(200 \mathrm{~mL})$ of biocathode BES was taken at 4 and $48 \mathrm{~h}$ of an operational cycle, and extracted by shaking with $200 \mathrm{~mL}$ of ethyl acetate at $150 \mathrm{rpm}$ for $2 \mathrm{~h}$, respectively. The former contained mainly CAP-acetyl and $\mathrm{CAP}$ while the latter contained mainly $\mathrm{AMCl} 2$ and $\mathrm{AMCl}$. Then the upper ethyl acetate layer was dried using a rotary evaporator at $45^{\circ} \mathrm{C}$ and the residues were dissolved into $2 \mathrm{~mL}$ methanol. The TLC with silica gel $60 \mathrm{HF} 254$ adopted methanol/chloroform $(20: 80 ; \mathrm{v} / \mathrm{v})$ as the mobile phase. The TLC purified samples were analyzed using a reversed phase liquid chromatography (Agilent 1200) with a quadropole timeof-flight mass spectrometry (QTOFMS) (Agilent 6520) detection in the negative ion mode, which performed on an Agilent Zorbax XDB C18 column $(1.8 \mu \mathrm{m} ; 2.1 \times 100 \mathrm{~mm})$ with methanol $/ \mathrm{H}_{2} \mathrm{O}(55: 45 ; \mathrm{v} / \mathrm{v})$ as the mobile phase at a flow rate of $0.15 \mathrm{~mL} / \mathrm{min}$ with $\mathrm{UV}$ detection at $250 \mathrm{~nm}$. 
The determination of chloride ion was performed by an ion chromatography (IC) (ICS-3000, Dionex, Sunnyvale, CA) equipped using an IonPac AG20 guard column $(2 \times 50 \mathrm{~mm}$ I.D. $)$ and an anion AS11-HC $(2 \times 250 \mathrm{~mm}$ I.D. $)$ analytical column with $\mathrm{KOH}$ at a flow rate of $1.0 \mathrm{~mL} / \mathrm{min}(0-7 \mathrm{~min}, 20$ $\mathrm{mM} \mathrm{KOH}$; 7-15 $\mathrm{min}, 30 \mathrm{mM} \mathrm{KOH}$ ) as the mobile phase. Samples were injected into the $100 \mu \mathrm{L}$ sample loop using an AS autosampler (Dionex).

Samples obtained from the cathodic chamber were filtered through a $0.45 \mu \mathrm{m}$ filter. Concentrations of CAP and transformation products were analyzed using a reverse-phase HPLC (model e2695, Waters Co., Milford, MA) with UV detection at $250 \mathrm{~nm}$ for $\mathrm{AMCl} 2$ and $\mathrm{AMCl}, 275 \mathrm{~nm}$ for CAP and CAP-acetyl, and $310 \mathrm{~nm}$ for $\mathrm{NO}$ and HOAM intermediates, respectively. The separation of CAP and transformation products was performed with a C18 column ( $5 \mu \mathrm{m} ; 5 \times 250 \mathrm{~mm}$, Waters Co.) and a mobile phase of methanol $/ \mathrm{H}_{2} \mathrm{O}(55: 45 ; \mathrm{v} / \mathrm{v})$ at a flow rate of $0.8 \mathrm{~mL} / \mathrm{min}$ at 30 ${ }^{\circ} \mathrm{C}$. To identify the products during CAP transformation, HPLC-MS/MS tests were performed. The samples of catholyte were collected at 10,36, and $48 \mathrm{~h}$ for biocathode BES tests and at 0 and $96 \mathrm{~h}$ for abiotic cathode BES tests. The collected cathlytes were centrifuged at $13000 \mathrm{~g}$ for $30 \mathrm{~min}$ and the supernatants were diluted by methanol prior to measurement. The HPLC-MS/MS (ion trap) (Thermo Finnigan LCQ Deca XP Max LC/MS, Germany) was equipped with an electrospray ionization source and operated in the positive/negative polarity mode. Separation was performed with a C18 column under the same condition as described above. The intermediates scanned in the normal mass range from $50 \mathrm{~m} / z$ (mass to charge ratio) to $500 \mathrm{~m} / z$ were separated and confirmed first by first-order MS with the full scan mode and further verified by tandem MS/ MS with single reaction monitoring mode.

The current (I) and CAP removal efficiency $\left(\mathrm{Er}_{\mathrm{CAP}}, \%\right)$ were calculated as described previously. ${ }^{36,37}$ The kinetics of CAP transformation was assumed to follow first-order reaction model as $C=C_{0} \mathrm{e}^{-k t}$, where $C$ is CAP concentration $(\mathrm{mg} / \mathrm{L})$ at time $t(\mathrm{~h})$ and $C_{0}$ is initial CAP concentration $(32 \mathrm{mg} / \mathrm{L})$. The rate constant $k(1 / \mathrm{h})$ was calculated by SigmaPlot v.11.0 software analysis. The half-life time $\left(t_{1 / 2}\right)$ of CAP was calculated using an equation: $t_{1 / 2}=0.693 / k^{42}$

Antibacterial Activity Measurement. After reaction of $160 \mathrm{~h}$, most CAP in catholyte was consumed. Catholyte (300 $\mathrm{mL}$ ) was withdrawn from the BES and then centrifugated at 13 $000 \mathrm{~g}$ for $30 \mathrm{~min}$ to collect supernatant. The supernatant was then dried by lyophilization. The residues were dissolved into $10 \mathrm{~mL}$ methanol, which was then concentrated to a final volume of $600 \mu \mathrm{L}$. The concentrated methanol solution was filtered via a sterile $0.22 \mu \mathrm{m}$ filter prior to antibacterial activity tests. The antibacterial activity of $\mathrm{CAP}$ and $\mathrm{AMCl}$ to bacterial strains was evaluated based on their toxicity on the viabilities of Escherichia coli strain DH5 $\alpha$ (a typical Gram-negative bacterium) and Shewanella oneidensis strain MR-1 (an electrogenic bacterium). Cells of both strains were harvested in their exponential growth phase, washed for three times using sterile phosphate buffer solution (PBS) (50 mM, pH 7.0), and then inoculated into $50 \mathrm{~mL}$ of 3-fold-diluted Luria-Bertani (LB) medium with the same cell concentrations based on optical density at $600 \mathrm{~nm}\left(\mathrm{OD}_{600 \mathrm{~nm}}\right)$ by a Shimadzu spectrometer (UV2550, Japan). Both the CAP and the AMCl were added to the 3-fold-diluted LB medium at the same concentration of 32 $\mathrm{mg} / \mathrm{L}$. The same medium without CAP and $\mathrm{AMCl}$ served as control. The antibacterial activity assay was performed in triplicates.

During the antibacterial activity assay tests, samples were collected every $3 \mathrm{~h}$. Biomass was collected by centrifugation of $1 \mathrm{~mL}$ cell suspension sample at $13000 \mathrm{~g}$ for $10 \mathrm{~min}$ and the pellets were resuspended in the $1 \mathrm{~mL}$ PBS ( $50 \mathrm{mM}$; pH 7.0) to measure $\mathrm{OD}_{600 \mathrm{~nm}}$ (Shimadzu UV2550 spectrometer, Japan).

Cyclic Voltammetry Analysis. Analysis of cyclic voltammetry (CV) was performed using an electrochemical workstation (model-660D, CH Instruments Inc. U.S.) equipped with three-electrode system. The cathode/biocathode and the anode of BES were used as the working and counter electrode, respectively. The SCE was the reference electrode. Concentration of CAP and glucose was $32 \mathrm{mg} / \mathrm{L}$ and $500 \mathrm{mg} / \mathrm{L}$, respectively, if applied. Cyclic voltammograms were recorded with the scan rate of $5 \mathrm{mV} / \mathrm{s}$ at $25{ }^{\circ} \mathrm{C}$ in all $\mathrm{CV}$ tests.

Electrochemical Dechlorination Mechanism Analysis. To verify the dechlorination mechanism of abiotic cathode $\mathrm{BES}$, one abiotic cathode reactor with catholyte containing only $5 \mathrm{mM}$ PBS and $200 \mathrm{mg} / \mathrm{L}$ CAP were tested at $-0.4 \mathrm{~V}$ (producing no $\mathrm{H}$ or $\mathrm{H}_{2}$ ) or at $-0.7 \mathrm{~V}$ (same as the present fedbatch tests) catholic potential (WMPG1000K8 multichannel potentiostat, WonATech Co., Ltd., Korea). The standard Hg/ $\mathrm{Hg}_{2} \mathrm{SO}_{4}$ reference electrode (R0401, Tianjin Aidahengsheng Technology Co., Ltd., China) was used for $\mathrm{Cl}^{-}$measurement to avoid disturbance by $\mathrm{Hg}_{2} \mathrm{Cl}_{2}$ and $\mathrm{KCl}$ in the SCE. The cathode effluents $(160 \mathrm{~h})$ under two voltages were analyzed by IC and HPLC.

Microbial Community Analysis. The samples of CAPreducing consortium $(10 \mathrm{~mL})$ and the biofilm on biocathode collected at the end of test were used for microbial community analysis. The total genomic DNA of the collected samples was extracted using a UNIQ-10 DNA Isolation Kit (Sangon Biotech Co., Ltd., Shanghai, China) according to the manufacturer's instructions. The PCR-denaturing gradient gel electrophoresis (DGGE) analysis was performed to target the V3 region of bacteria as described previously. ${ }^{43}$ Fourteen bands were sequenced using an ABI 3730XL sequencer (Applied Biosystems, Foster, CA) by Sangon Biotech (Shanghai, China). The obtained sequences were deposited to GenBank with accession numbers being JQ319508 to JQ319522. Analysis of $16 \mathrm{~S}$ rRNA gene sequences was conducted according to previous method. ${ }^{36}$

\section{RESULTS AND DISCUSSION}

Bioelectrochemical Reduction of CAP. Three different modes were tested for comparison in this study: biocathode BES with closed circuit and external power source (biocathode in short), BES with biocathode at opened circuit (opened biocathode), and BES with an abiotic cathode (abiotic cathode). The sequence of CAP removal rate $\left(k_{\mathrm{CAP}}\right)$ was: biocathode $>$ opened biocathode $>$ abiotic cathode (Figure 1). In abiotic BES control (without current and microbes), the CAP concentration was declined slightly without detectable intermediates/products. The slight decline in CAP concentration was attributable to CAP adsorption onto carbon cloth and/or plastic surface of reactor parts. Conversely, the $\mathrm{Er}_{\mathrm{CAP}}$ of the biocathode BES was $87.1 \pm 4.2 \%$ at $4 \mathrm{~h}$ and $96.0 \pm 0.9 \%$ at $24 \mathrm{~h}$. $\mathrm{Er}_{\mathrm{CAP}}$ of the abiotic cathode BES was only $73.0 \pm 3.2 \%$ at $24 \mathrm{~h}$. This indicated that more CAP was removed in biocathode BES within $4 \mathrm{~h}$ than abiotic cathode within $24 \mathrm{~h}$. The BES with abiotic cathode and biocathode had similar cathode potentials (about $-0.7 \mathrm{~V}$ vs SHE) but the initial current of biocathode 


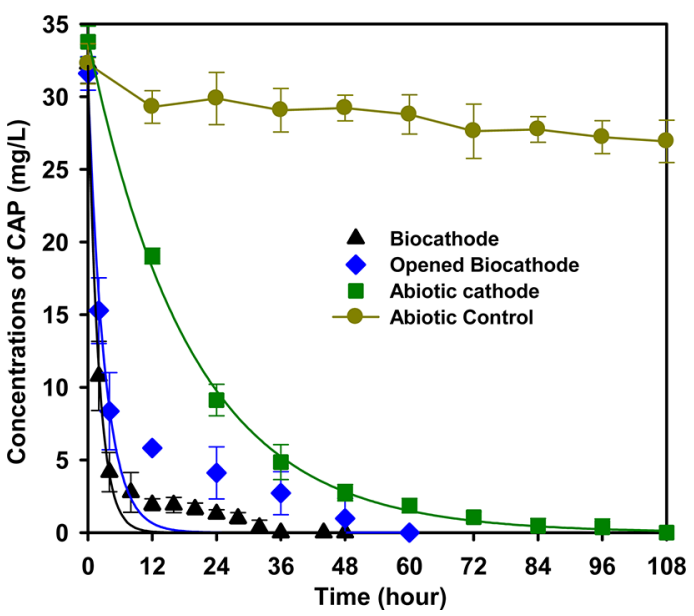

Figure 1. Reduction of CAP under different operating conditions in fed batch BES. Lines were fitted to apparent first order reaction model for kinetic analysis. The respective CAP removal rate $(k)$ and half-life time $\left(t_{1 / 2}\right)$ under different conditions are: biocathode, $R^{2}=0.9798, k=$ $0.5197 \pm 0.0533, t_{1 / 2}=1.33 \mathrm{~h}$; abiotic cathode, $R^{2}=0.9986, k=0.0520$ $\pm 0.0008, t_{1 / 2}=13.33 \mathrm{~h}$; and open biocathode, $R^{2}=0.9309, k=0.3222$ $\pm 0.0652, t_{1 / 2}=2.16 \mathrm{~h}$. Test conditions: ambient temperature $(26 \pm 2$ $\left.{ }^{\circ} \mathrm{C}\right)$; initial CAP concentrations of $32 \mathrm{mg} / \mathrm{L}$.

was 3.2 times as that with abiotic cathode (SI Figure S2). Further comparison was done with the opened biocathode BES to verify the role of electrochemical reaction. The $k_{\mathrm{CAP}}$ of biocathode was 1.6 times to that of opened biocathode although both had identical biofilm (Figure 1), indicating that the generation of electron from anode and applied external voltage of $0.5 \mathrm{~V}$ did enhance the CAP reduction. Among the three operational modes, biocathode mode showed the highest $k_{\mathrm{CAP}}$ and $\mathrm{Er}_{\mathrm{CAP}}$. The electrode likely provided a persistent extracellular electron while glucose in cathode acted as intracellular electron donor and carbon source for cathodophilic bacteria that involved in CAP reduction metabolism.

Reduction Products of CAP. The products of CAP transformation with biocathode (in both closed and opened modes) were very different from those of produced with abiotic cathode (Figure 2). AMCl2 was produced rapidly as CAP was reduced in the biocathode $\mathrm{BES}$. Conversely, $\mathrm{AMCl} 2$ was accumulated slowly in the abiotic cathode BES with nitroso (NO) and hydroxylamino (HOAM) as the additional intermediates (Figures 2A and 2D). The peak concentrations of $\mathrm{AMCl} 2$ produced from $\mathrm{CAP}$ in the abiotic cathode BES and opened biocathode was much lower than that in biocathode BES (Figure 2A). One intermediate, CAP-acetyl, was found only in both opened and closed biocathode BES (Figure 2C), indicating that it was produced from bioactivity since CAP acetyltransferase catalyzes acetylation of 3-hydroxyl of CAP while 3-hydroxyl acetylated CAP can also be transformed reversibly to 1-hydroxyl acetylated $\mathrm{CAP} .{ }^{44}$ In prolonged test, the produced $\mathrm{AMCl} 2$ was further reductively dechlorinated to $\mathrm{AMCl}$ under all BES modes (Figure 2B). The products mentioned herein were identified with HPLC-MS/MS, LCQTOFMS and assisted with IC as demonstrated below.

Antibacterial Activity Elimination Due to CAP Reduction. The antibacterial activity assay was performed using two selected bacterial strains (E. coli strain DH5 $\alpha$ and S. oneidensis

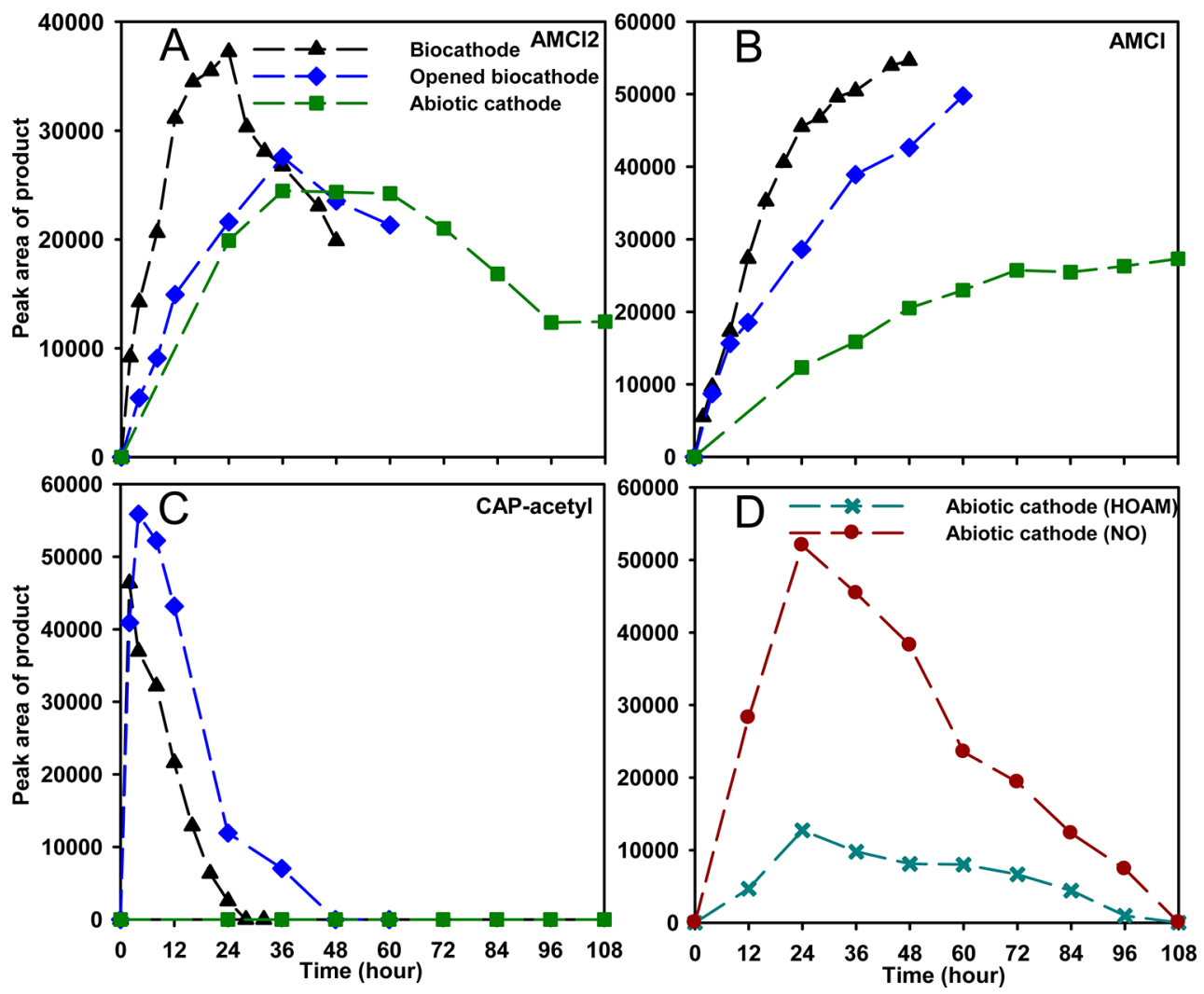

Figure 2. Major CAP transformation products in fed-batch BES with abiotic cathode and biocathode (opened and closed circuit). AMCl2: reduced amine product; NO: nitroso intermediate; HOAM: hydroxylamino intermediate; AMCl: dechlorinated AMCl2; CAP-acetyl (acetylation of 1hydroxyl or 3-hydroxyl of CAP to form CAP-acetyl). 
strain MR-1). The growth of both strains was completely inhibited in the presence of CAP at $32 \mathrm{mg} / \mathrm{L}$, but was not in the presence of $\mathrm{AMCl}$ at the same concentration (Figure 3).

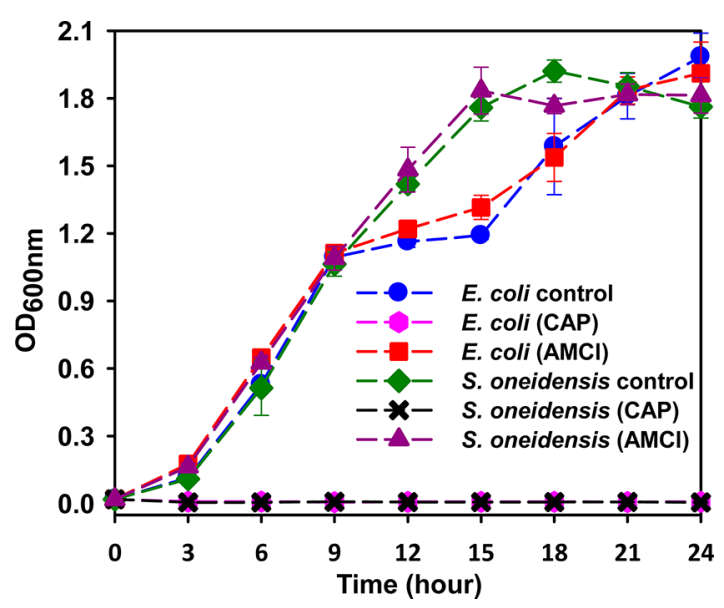

Figure 3. Effect of CAP $(32 \mathrm{mg} / \mathrm{L})$ and $\mathrm{AMCl}(32 \mathrm{mg} / \mathrm{L})$ on the growth of E. coli DH5 $\alpha$ and S. oneidensis MR-1. The normal growth of two tested strains in the 3-fold-diluted LB medium was also evaluated.

This observation suggests that the end product $\mathrm{AMCl}$ has much less antibacterial activity than CAP. The similar observation indicated that $\mathrm{AMCl} 2$ lacked antibacterial activity. ${ }^{18} \mathrm{As} \mathrm{AMCl}$ is less toxic to microorganisms and relatively easier to be biodegraded, thus, the reduction of $\mathrm{CAP}$ to $\mathrm{AMCl}$ would have ecological significance in the elimination of the selection pressure of antibiotic for the generation of antibiotic resistant bacteria/genes in the environments. ${ }^{16,45}$ On the other hand, HOAM and NO, the intermediates of CAP reduction in abiotic cathode BES, are toxic to microorganisms, ${ }^{46}$ and can retain their antibacterial activity in another kind of nitroaromatic antibiotic nitroimidazoles. ${ }^{47}$ As mentioned above, neither
HOAM nor NO was detected in the biocathode BES, therefore, the biocathode is likely superior to abiotic cathode in the elimination of antibacterial activity from CAP-containing wastewaters.

CAP Reduction Pathways. The reaction products of CAP reduction were identified by the HPLC-MS/MS, LC-QTOFMS and IC analysis. The detailed analytical procedures for the identification are available in the SI (Figures S3-S8). In the abiotic cathode BES, CAP was reduced to $\mathrm{AMCl} 2$ with $\mathrm{HOAM}$ and $\mathrm{NO}$ as accumulated intermediates. In the biocathode $\mathrm{BES}$, $\mathrm{CAP}$ was selectively converted to $\mathrm{AMCl} 2$ with one identified intermediate, acetylated CAP (CAP-acetyl) (SI Figure S5), which was accumulated only in the biocathode BES (peaked at $2 \mathrm{~h}$ ) and opened biocathode BES (peaked at $4 \mathrm{~h}$ ) (Figure 2C). This observation indicated that the acetylation of 3-hydroxyl of CAP occurred with formation of CAP-acetyl as part of the metabolism by the microbes in biocathode. Some bacteria have CAP acetyltransferase which catalyzes acetylation of 3-hydroxyl group. ${ }^{44}$ The CAP-acetyl was further reduced to its amine form and then be rapidly converted to AMC12 within $48 \mathrm{~h}$ in biocathode BES (Figure 2C).

Two amine products of CAP (AMCl2) and a novel dechlorinated product (AMCl) were identified in this study (SI Figure S6). In both the opened and closed biocathode BES $\mathrm{CAP}$ was reduced to $\mathrm{AMCl} 2$ and then was dechlorinated to $\mathrm{AMCl}$ (Figure 2B). Diverse dehalogenase in target chlorinated alkanes and alkanoic acids (similar as the side chain of CAP) ${ }^{48}$ may be involved in the dechlorination process in the biocathode BES. We used the abiotic cathode BES with catholyte containing only $5 \mathrm{mM}$ PBS and $200 \mathrm{mg} / \mathrm{L} \mathrm{CAP} \mathrm{to}$ analyze abiotic electrochemical dechlorination mechanism. At $-0.4 \mathrm{~V}$ cathodic potential, after $160 \mathrm{~h}$ reaction in the abiotic cathode BES, $98.5 \%$ of CAP was transformed but failed to effectively dechlorinate $\mathrm{AMCl} 2$. Conversely, CAP was effectively reduced to $\mathrm{AMCl} 2$ and then to $\mathrm{AMCl}$ at $-0.7 \mathrm{~V}$

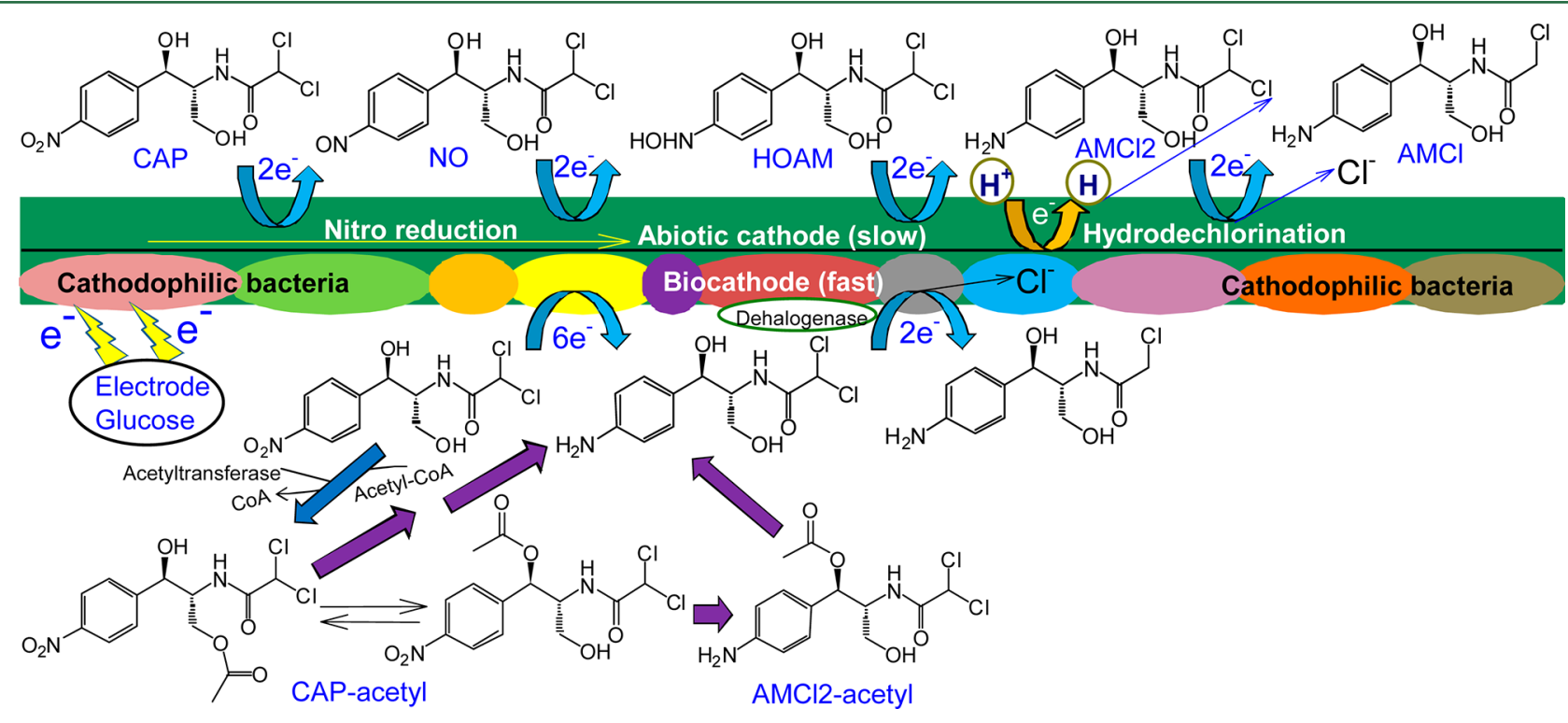

Figure 4. Proposed pathway of the cathodic CAP reduction in the BES. Green bar represents the abiotic cathode and biocathode (attached diverse cathodophilic bacteria). Electrode and glucose are both the electron donor for cathodophilic bacteria for reduction of CAP and glucose also works as carbon source for the cathode biofilm metabolism. Purple arrows indicates the occurred reduction reaction was presumed in this study. CAP-acetyl was the unique product found in biocatalyzed process, while NO and HOAM intermediates were only detected in abiotic electrochemical process. Dehalogenase likely catalysis of $\mathrm{AMCl} 2$ to $\mathrm{AMCl}$ as pure microbial reduction also has the dechlorination activity. Electrochemical hydrodechlorination responsible for the dechlorination of $\mathrm{AMCl} 2$ to $\mathrm{AMCl}$ in abiotic cathode $\mathrm{BES}$. 

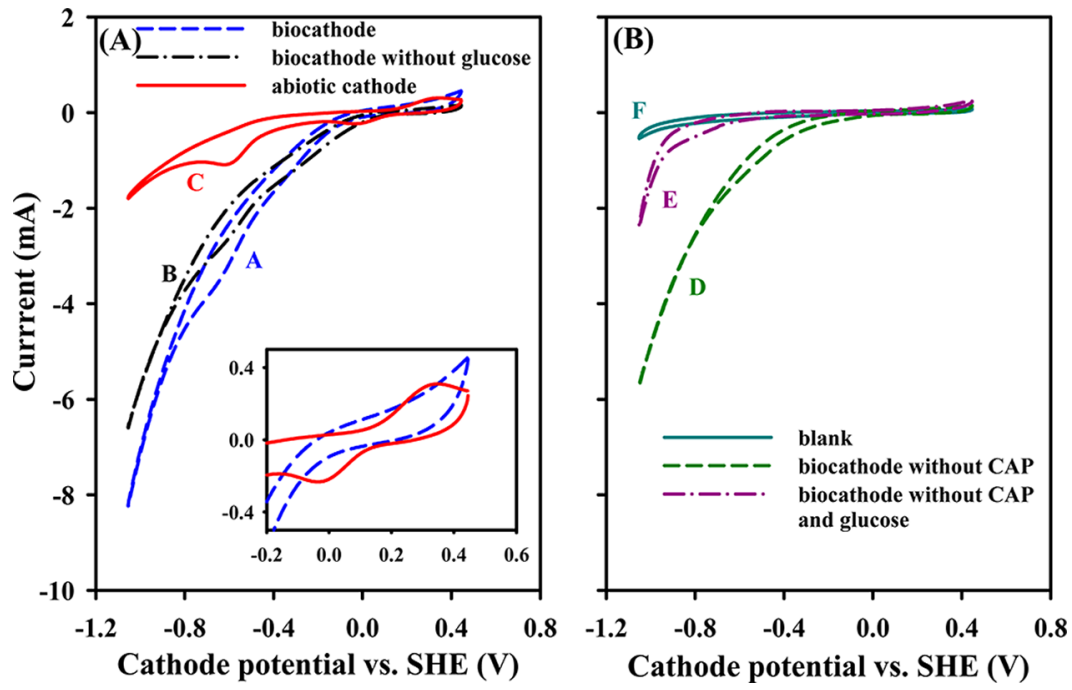

Figure 5. Cyclic voltammograms of biocathode and abiotic cathode in the presence of CAP. Solid line: abiotic cathode; dashed line: biocathode; dashed-dotted line: biocathode without glucose. Insert: enlarging for comparison of biocathode and abiotic cathode in the potential window between $0.6 \mathrm{~V}$ and $-0.2 \mathrm{~V}(\mathrm{~A})$. Cyclic voltammograms of biocathode in the absence of CAP. Dashed line: without CAP only; dashed-dotted line: without CAP and glucose; solid line: blank, which represented the case without bacteria in despite of the presence of glucose, as CVs of abiotic cathode with or without glucose did not have obvious difference here (B). Concentration of CAP and glucose was $32 \mathrm{mg} / \mathrm{L}$ and $500 \mathrm{mg} / \mathrm{L}$, respectively, if used. Scan rate for all tests was $5 \mathrm{mV} / \mathrm{s}$.

Table 1. Phylogenetic Identification of Prominent DGGE Bands Based on the V3 Region of the 16S rRNA Gene

\begin{tabular}{|c|c|c|c|}
\hline $\begin{array}{l}\text { band (accession } \\
\text { no.) }\end{array}$ & closest type strain in GenBank Database (accession no.) & phylum/class & similarity (\%) \\
\hline 1 (JQ319508) & Elizabethkingia miricola GTC862 ${ }^{\mathrm{T}}$ (AB071953) & bacteroidetes/flavobacteriia & 97.88 \\
\hline 2 (JQ319509) & Elizabethkingia miricola GTC862 $2^{\mathrm{T}}$ (AB071953) & bacteroidetes/flavobacteriia & 97.87 \\
\hline 3-1 (JQ319510) & Fluviicola taffensis DSM $16823^{\mathrm{T}}$ (CP002542) & bacteroidetes/flavobacteriia & 96.70 \\
\hline 3-2 (JQ319511) & Alcaligenes faecalis subsp. parafaecalis $\mathrm{G}^{\mathrm{T}}$ (AJ242986) & $\begin{array}{l}\text { proteobacteria } / \beta \\
\text { proteobacteria }\end{array}$ & 98.45 \\
\hline 4 (JQ319512) & $\begin{array}{l}\text { Tepidimicrobium ferriphilum SB91 }{ }^{\mathrm{T}} \text { (AY656718) or Peptoniphilus methioninivorax RRL B-23883 } \\
\text { (GU440754) }\end{array}$ & firmicutes/clostridia & 94.68 \\
\hline 5 (JQ319513) & $\begin{array}{l}\text { Salmonella bongori NCTC } 12419^{\mathrm{T}} \text { (FR877557) or Enterobacter cloacae subsp. dissolvens LMG } \\
2683^{\mathrm{T}} \text { (Z96079) }\end{array}$ & $\begin{array}{l}\text { proteobacteria } / \gamma- \\
\text { proteobacteria }\end{array}$ & $\begin{array}{l}97.41 \text { (or } \\
97.40)\end{array}$ \\
\hline 6 (JQ319514) & Stenotrophomonas nitritireducens $\mathrm{L}^{\mathrm{T}}$ (AJ012229) & $\begin{array}{l}\text { proteobacteria } / \gamma- \\
\text { proteobacteria }\end{array}$ & 100.00 \\
\hline 7 (JQ319515) & Ferribacterium limneticum cda- $1^{\mathrm{T}}(\mathrm{Y} 17060)$ or Dechloromonas denitrificans $\mathrm{ED}^{\mathrm{T}}(\mathrm{AJ} 318917)$ & $\begin{array}{l}\text { proteobacteria } / \beta \text { - } \\
\text { proteobacteria }\end{array}$ & 95.88 \\
\hline 8 (JQ319516) & Devosia psychrophila Cr7-05 ${ }^{\mathrm{T}}$ (GU441678) & $\begin{array}{l}\text { proteobacteria } / \alpha \text { - } \\
\text { proteobacteria }\end{array}$ & 100.00 \\
\hline 9 (JQ319517) & Clavibacter michiganensis subsp. insidiosus LMG $3663^{\mathrm{T}}$ (U09761) & $\begin{array}{l}\text { actinobacteria/ } \\
\text { actinobacteridae }\end{array}$ & 100.00 \\
\hline $10(\mathrm{JQ3} 19518)$ & Pseudomonas beteli ATCC $19861^{\mathrm{T}}$ (AB021406) & $\begin{array}{l}\text { proteobacteria } / \gamma- \\
\text { proteobacteria }\end{array}$ & 96.30 \\
\hline $11(\mathrm{JQ3} 19519)$ & Ochrobactrum lupini LUP2 $1^{\mathrm{T}}$ (AY457038) & $\begin{array}{l}\text { proteobacteria } / \alpha \text { - } \\
\text { proteobacteria }\end{array}$ & 98.12 \\
\hline $12(\mathrm{JQ} 319520)$ & Myroides odoratus ATCC $4651^{\mathrm{T}}$ (M58777) & bacteroidetes/flavobacteriia & 97.01 \\
\hline 13 (JQ319521) & Pseudomonas putida DSM $291^{\mathrm{T}}$ (Z76667) & $\begin{array}{l}\text { proteobacteria } / \gamma \text { - } \\
\text { proteobacteria }\end{array}$ & 100.00 \\
\hline $14(\mathrm{JQ} 319522)$ & Flavobacterium lindanitolerans $\mathrm{IP}-10^{\mathrm{T}}$ (EF424395) & bacteroidetes/flavobacteriia & 100.00 \\
\hline
\end{tabular}

(SI Figure S7). Stoichiometrically complete reduction of 200 $\mathrm{mg} / \mathrm{L}(0.62 \mathrm{mM}) \mathrm{CAP}$ to $\mathrm{AMCl}$ should produce $21.94 \mathrm{mg} / \mathrm{L}$ $(0.62 \mathrm{mM}) \mathrm{Cl}^{-}$. Hence, the $\mathrm{Cl}^{-}$recovery efficiency in abiotic cathode BES were $107.8 \%$ and $15.7 \%$ at $-0.7 \mathrm{~V}$ and $-0.4 \mathrm{~V}$ cathodic potential, respectively (SI Figure S7). This observation indicated that electrochemical hydrodechlorination mechanism ${ }^{49}$ was incorporated in the abiotic dechlorination reaction. Complete dechlorination of $\mathrm{AMCl}$ to $\mathrm{AM}$ may be possible but requires further study such as via decreasing cathode potential to below $-0.7 \mathrm{~V}$ or enriching specific dechlorinating microbial consortium. This is the first report for microbial or pure electrochemical dechlorination of amine product of CAP. We proposed the pathway of CAP reduction in the cathodic BES based on the intermediates and products identified (Figure 4). In the abiotic cathode BES, CAP was reduced to $\mathrm{AMCl} 2$ with the HOAM and $\mathrm{NO}$ as intermediates, and the formed $\mathrm{AMCl} 2$ can be further dechlorinated to $\mathrm{AMCl}$ via electrochemical hydrodechlorination. In the biocathode BES, CAP was transformed to $\mathrm{AMCl} 2$ without toxic intermediate accumulation and then $\mathrm{AMCl} 2$ was converted to $\mathrm{AMCl}$ likely by dehalogenase of microorganisms. In the biocathode BES, CAPacetyl was found as an intermediate and eventually disappeared. 
The dechloridation pathway of CAP in abiotic cathode and biocathode BES is significantly different, and biocathode BES shows higher dechloridation rate from $\mathrm{AMCl} 2$ to $\mathrm{AMCl}$ than abiotic cathode BES.

Microbial Role in CAP Reduction on Biocathode. The CV tests with CAP in abiotic BES was started at around $-0.3 \mathrm{~V}$. The peak potential for CAP reduction was observed at about $-0.6 \mathrm{~V}$ (peak a). An oxidation peak (peak b) appeared in the return half-cycle, accompanying with a new reduction peak (peak c') coming out in the second cycle (SI Figure S9). Similar $\mathrm{CV}$ behavior was observed during $\mathrm{CAP}$ reduction on the boron-doped diamond electrode ${ }^{50}$ and that of the other nitro compounds on carbon based electrode, ${ }^{51}$ whose pair redox peaks was proposed as the reversible reaction of the hydroxylamine and nitroso derivatives. We proposed that the intermediates HOAM and $\mathrm{NO}$ in abiotic BES were contributing to the peak b' and peak c', respectively, in the $\mathrm{CV}$ measurements.

Compared to the $\mathrm{CV}$ profile of abiotic cathode (Figure 5A, curve $\mathrm{C}$ ), the $\mathrm{CV}$ of biocathode, despite of the presence of glucose or not (Figure 5A, curves $\mathrm{A}$ and $\mathrm{B}$ ), revealed much higher positive onset potential $(0 \mathrm{~V}$ vs $-0.3 \mathrm{~V})$ with the increase in cathodic current. No increase in cathodic current was observed before $-0.6 \mathrm{~V}$ in the biocathode $\mathrm{CV}$ in the nutrient medium (Figure 5B, curve $\mathrm{E}$ ). Therefore, the onset potential of $0 \mathrm{~V}$ in $\mathrm{CV}$ noted for biocathode should be at least partially contributed by the CAP reduction. Based on the further negative scanning on cathode potential, much higher cathodic current was generated in biocathode than that in abiotic cathode, indicating the higher electrochemical activity for CAP reduction on biocathode to be revealed below $-0.6 \mathrm{~V}$ (Figure 5A). The enhancement of cathodic current and the positive shift of onset potential for the cathodic current indicated that the cathodic biofilm catalyzed the bioelectrochemical CAP reduction. The hydrogen evolution is theoretically inactive at the cathode potential higher than $-0.41 \mathrm{~V}$ at neutral $\mathrm{pH}^{52}$ The noted onset potential of CAP reduction by biocathode $(0 \mathrm{~V})$ suggested that the electron transfer from cathode to microbial cells was not via cathodic produced hydrogen. ${ }^{30}$ Additionally, the pair peak involved in the redox reaction of HOAM and NO intermediates only found in the $\mathrm{CV}$ profile of abiotic cathode were not observed in the $\mathrm{CV}$ of biocathode (Figure 5A, curve A). This observation is consistent with the no-detection of HOAM and NO intermediates in the biocathode BES. In the absence of CAP, addition of glucose caused the pronounced increase of cathodic current of biocathode at a more positive potential (Figure 5B, curve D compared to curve E), indicating certain cathodic reactions to occur in the presence of glucose.

Microbial Communities of Cathode Biofilm. Succession of the bacterial community from inoculum to cathode biofilm was revealed by $16 \mathrm{~S}$ rRNA gene analysis (Table 1 and SI Figure S10). The DGGE bands were most closely affiliated with the $16 \mathrm{~S}$ rRNA genes of type species from Bacteroidetes (Flavobacteriia) and Proteobacteria $(\alpha, \beta$, and $\gamma$-Proteobacteria), both were dominated in the inoculum and cathode biofilm. The microbial community in the cathode biofilm was different from the inoculated culture. Two major bands, affiliated to Salmonella bongori NCTC $12419^{\mathrm{T}}$ (or Enterobacter cloacae subsp. dissolvens LMG 2683 ${ }^{\mathrm{T}}$ ) and Clavibacter michiganensis subsp. insidiosus LMG $3663^{\mathrm{T}}$, respectively, were noted in the cathode biofilm but were not observed in the inoculum. Both genus were capable of reducing nitroaromatic compounds with nitroreductase. ${ }^{53,54}$ Species belonged to Enterobacter are capable of reducing nitrobenzene or $\mathrm{O}_{2}$ in the cathode. ${ }^{36,55,56}$ Some strains of Pseudomonas spp. appeared in both the inoculum and cathode biofilm, which were also reported to reduce nitroaromatic compounds with nitroreductase ${ }^{54}$ and could directly uptake electron from the electrode for nitrate and sulfate reduction. ${ }^{57,58}$ This suggested that Pseudomonas spp. on biocathode may involve in the bioelectrochemical reduction of CAP. Metabolites (e.g., pyocyanin, phenazine-1-carboxamide, and biosurfactants)-based mutualism between Pseudomonas and Enterobacter species or Gram-positive species formed coculture to enhance current generation in BES fed with glucose or acetate. $^{59,60}$ One species in the cathode biofilm has the highest $16 \mathrm{~S}$ rRNA gene sequence similarity with type strain Dechloromonas denitrificans $\mathrm{ED}^{\mathrm{T}}$ (or Ferribacterium limneticum cda- ${ }^{\mathrm{T}}$ ). Dechloromonas agitate $\mathrm{CKB}$ formed biocathode was reported to be capable of reducing perchlorate with 2,6anthraquinone disulfonate as an electron shuttle mediator in a BES. $^{35}$ The cathodophilic functional microbes could reduce CAP with nitroreductase and dehalogenase as terminal reducases and obtain electrons directly from electrode or metabolite-based mutualism between these cathodophilic microbes. Further study is needed to understand the mechanism of electron transfer from electrode surface to cathodophilic functional microbes in order to enhance the efficiency of the CAP-reducing biocathode in BES. Additionally, several species in the inoculum disappeared or nearly disappeared after 4 months enrichment but they were found on the biocathode (SI Figure S10). The microbial community structure in the BES was changed with continuous electrochemical stimulation.

\section{OUTLOOK}

Factually, wastewater treatment plants are important point sources of antibiotic entry into the environment. ${ }^{5,61}$ In this study, we demonstrated the feasibility of using bioelectrochemical transformation to convert CAP to AMCl2, which was further dechlorinated to $\mathrm{AMCl}$ in biocathode BES. Along with this reduction, the antibacterial activity was eliminated in the biocathode BES, which also enhanced biodegradability of the CAP-containing wastewaters. Reduction of nitro group of CAP and $\mathrm{AMCl} 2$ dechloridation with biocathode $\mathrm{BES}$ showed higher efficiency than abiotic cathode BES. Bacterial dehalogenases catalyze the cleavage of carbon-halogen bonds and play key roles in the detoxification of chlorinated compounds and even in the energy catabolism of strictly anaerobic bacteria ${ }^{22,48,62}$ such as cathodophilic bacteria using $\mathrm{AMCl} 2$ as electron acceptor. Nitro group reduction combined with dechlorination reaction enhanced the detoxication efficiency of CAP in BES. The results of this study demonstrated the feasibility of use of electrochemical bioreduction in biocathode BES to detoxify chlorinated nitro-group compounds such as CAP. The biocathode BES could have potential in advanced wastewater treatment for nitroaromatic antibiotic, explosives, pesticides, and herbicides. Potential target nitroaromatic antibiotic may also include nitrofurans, nitroimidazoles, phenylpyrrole, aureothin, neoaureothin, thaxtomin, and azomycin. Such a process has its advantage over conventional wastewater treatment process on the minimization of the evolution of novel antibiotic resistant bacteria/genes in the environments. 


\section{ASSOCIATED CONTENT}

\section{S Supporting Information}

Identification of CAP reductive intermediates and products and Figures S1-S10. This material is available free of charge via the Internet at http://pubs.acs.org.

\section{AUTHOR INFORMATION}

\section{Corresponding Author}

*Phone/fax: +86-451-86282195. E-mail: djlee@ntu.edu.tw (D. J. L.); waj0578@hit.edu.cn (A. J. W.).

\section{Author Contributions}

${ }^{\dagger} \mathrm{B}$. Liang and H. Y. Cheng contributed equally to this work.

Notes

The authors declare no competing financial interest.

\section{ACKNOWLEDGMENTS}

We gratefully acknowledge the financial support by the National Natural Science Foundation of China (Grant No.51078100), by National Science Foundation for Distinguished Young Scholars (Grant No.51225802), by National Creative Research Groups Project (Grant No.51121062), by the National High-tech R\&D Program of China (863 Program, Grant No. 2011AA060904), by The Ph.D. Programs Foundation of Ministry of Education of China (20102302110055), by "Hundred Talents Program" of the Chinese Academy of Sciences, and by Heilongjiang Science Foundation for Distinguished Young Scholars (Grant No. JC201003). Dr. Wei-Min Wu was a guest professor at Harbin Institute of Technology during this study.

\section{REFERENCES}

(1) Andam, C. P.; Fournier, G. P.; Gogarten, J. P. Multilevel populations and the evolution of antibiotic resistance through horizontal gene transfer. FEMS Microbiol. Rev. 2011, 35 (5), 756-767.

(2) Davies, J.; Davies, D. Origins and evolution of antibiotic resistance. Microbiol. Mol. Biol. Rev. 2010, 74 (3), 417-433.

(3) Feder, H. M.; Osier, C.; Maderazo, E. G. Chloramphenicol-A review of its use in clinical-practice. Rev. Infect Dis. 1981, 3 (3), 479491.

(4) Martelli, A.; Mattioli, F.; Pastorino, G.; Robbiano, L.; Allavena, A.; Brambilla, G. Genotoxicity testing of chloramphenicol in rodent and human-cells. Mutat. Res. 1991, 260 (1), 65-72.

(5) Leung, H. W.; Minh, T. B.; Murphy, M. B.; Lam, J. C. W.; So, M. K.; Martin, M.; Lam, P. K. S.; Richardson, B. J. Distribution, fate and risk assessment of antibiotics in sewage treatment plants in Hong Kong, South China. Environ. Int. 2012, 42, 1-9.

(6) Peng, X.; Wang, Z.; Kuang, W.; Tan, J.; Li, K. A preliminary study on the occurrence and behavior of sulfonamides, ofloxacin and chloramphenicol antimicrobials in wastewaters of two sewage treatment plants in Guangzhou, China. Sci. Total Environ. 2006, 371 (1-3), 314-322.

(7) Minh, T. B.; Leung, H. W.; Loi, I. H.; Chan, W. H.; So, M. K.; Mao, J. Q.; Choi, D.; Lam, J. C. W.; Zheng, G.; Martin, M.; Lee, J. H. W.; Lam, P. K. S.; Richardson, B. J. Antibiotics in the Hong Kong metropolitan area: Ubiquitous distribution and fate in Victoria Harbour. Mar. Pollut. Bull. 2009, 58 (7), 1052-1062.

(8) Lin, A.; Yu, T.; Lin, C. Pharmaceutical contamination in residential, industrial, and agricultural waste streams: Risk to aqueous environments in Taiwan. Chemosphere 2008, 74 (1), 131-141.

(9) Xu, W.; Zhang, G.; Li, X.; Zou, S.; Li, P.; Hu, Z.; Li, J. Occurrence and elimination of antibiotics at four sewage treatment plants in the Pearl River Delta (PRD), South China. Water Res. 2007, 41 (19), 4526-4534.

(10) Choi, K.; Kim, Y.; Jung, J.; Kim, M. H.; Kim, C. S.; Kim, N. H.; Park, J. Occurrences and ecological risks of roxithromycin, trimethoprim, and chloramphenicol in the Han River, Korea. Environ. Toxicol. Chem. 2008, 27 (3), 711-719.

(11) Sui, Q.; Huang, J.; Deng, S.; Yu, G.; Fan, Q. Occurrence and removal of pharmaceuticals, caffeine and DEET in wastewater treatment plants of Beijing, China. Water Res. 2010, 44 (2), 417-426.

(12) Sui, Q.; Huang, J.; Deng, S.; Chen, W.; Yu, G. Seasonal variation in the occurrence and removal of pharmaceuticals and personal care products in different biological wastewater treatment processes. Environ. Sci. Technol. 2011, 45 (8), 3341-3348.

(13) Liu, H.; Zhang, G.; Liu, C. Q.; Li, L.; Xiang, M. The occurrence of chloramphenicol and tetracyclines in municipal sewage and the Nanming River, Guiyang City, China. J. Environ. Monit. 2009, 11 (6), 1199-1205.

(14) Parsley, L. C.; Consuegra, E. J.; Kakirde, K. S.; Land, A. M.; Harper, W. F.; Liles, M. R. Identification of diverse antimicrobial resistance determinants carried on bacterial, plasmid, or viral metagenomes from an activated sludge microbial assemblage. Appl. Environ. Microbiol. 2010, 76 (11), 3753-3757.

(15) Xi, C.; Zhang, Y.; Marrs, C. F.; Ye, W.; Simon, C.; Foxman, B.; Nriagu, J. Prevalence of antibiotic resistance in drinking water treatment and distribution systems. Appl. Environ. Microbiol. 2009, 75 (17), 5714-5718.

(16) Zhang, X. X.; Zhang, T.; Fang, H. H. P. Antibiotic resistance genes in water environment. Appl. Microbiol. Biotechnol. 2009, 82 (3), 397-414.

(17) Smith, G. N.; Worrel, C. S. Reduction of chloromycetin and related compounds by Escherichia coli. J. Bacteriol. 1953, 65 (3), 313317.

(18) Smith, A. L.; Erwin, A. L.; Kline, T.; Unrath, W. C. T.; Nelson, K.; Weber, A.; Howald, W. N. Chloramphenicol is a substrate for a novel nitroreductase pathway in Haemophilus influenzae. Antimicrob. Agents Chemother. 2007, 51 (8), 2820-2829.

(19) Sun, M.; Reible, D. D.; Lowry, G. V.; Gregory, K. B. Effect of applied voltage, initial concentration, and natural organic matter on sequential reduction/oxidation of nitrobenzene by graphite electrodes. Environ. Sci. Technol. 2012, 46 (11), 6174-6181.

(20) Donlon, B. A.; Razo-Flores, E.; Lettinga, G.; Field, J. A. Continuous detoxification, transformation, and degradation of nitrophenols in upflow anaerobic sludge blanket (UASB) reactors. Biotechnol. Bioeng. 1996, 51 (4), 439-449.

(21) Brown, D.; Laboureur, P. The aerobic biodegradability of primary aromatic amines. Chemosphere 1983, 12, 405-414.

(22) Mohn, W. W.; Tiedje, J. M. Microbial reductive dehalogenation. Microbiol. Rev. 1992, 56 (3), 482-507.

(23) Chatzitakis, A.; Berberidou, C.; Paspaltsis, I.; Kyriakou, G.; Sklaviadis, T.; Poulios, I. Photocatalytic degradation and drug activity reduction of chloramphenicol. Water Res. 2008, 42 (1-2), 386-394.

(24) Badawy, M. I.; Wahaab, R. A.; El-Kalliny, A. S. Fenton-biological treatment processes for the removal of some pharmaceuticals from industrial wastewater. J. Hazard. Mater. 2009, 167 (1-3), 567-574.

(25) Singh, K. P.; Singh, A. K.; Gupta, S.; Rai, P. Modeling and optimization of reductive degradation of chloramphenicol in aqueous solution by zero-valent bimetallic nanoparticles. Environ. Sci. Pollut. Res. Int. 2012, 19 (6), 2063-2078.

(26) Lin, L.; Yuan, S.; Chen, J.; Wang, L.; Wan, J.; Lu, X. Treatment of chloramphenicol-contaminated soil by microwave radiation. Chemosphere 2010, 78 (1), 66-71.

(27) Aulenta, F.; Tocca, L.; Verdini, R.; Reale, P.; Majone, M. Dechlorination of trichloroethene in a continuous-flow bioelectrochemical reactor: Effect of cathode potential on rate, selectivity, and electron transfer mechanisms. Environ. Sci. Technol. 2011, 45 (19), 8444-8451.

(28) Lohner, S. T.; Becker, D.; Mangold, K. M.; Tiehm, A. Sequential reductive and oxidative biodegradation of chloroethenes stimulated in a coupled bioelectro-process. Environ. Sci. Technol. 2011, 45 (15), 6491-6497.

(29) Strycharz, S. M.; Gannon, S. M.; Boles, A. R.; Franks, A. E.; Nevin, K. P.; Lovley, D. R. Reductive dechlorination of 2-chlorophenol 
by Anaeromyxobacter dehalogenans with an electrode serving as the electron donor. Environ. Microbiol. Rep. 2010, 2 (2), 289-294.

(30) Huang, L.; Chai, X.; Quan, X.; Logan, B. E.; Chen, G. Reductive dechlorination and mineralization of pentachlorophenol in biocathode microbial fuel cells. Bioresour. Technol. 2012, 111, 167-174.

(31) Cui, D.; Kong, F. Y.; Liang, B.; Cheng, H. Y.; Liu, D.; Sun, Q.; Wang, A. J. Decolorization of azo dyes in dual-chamber biocatalyzed electrolysis systems seeding with enriched inoculum. J. Environ. Anal. Toxicol. 2011, S3, 001.

(32) Sun, J. A.; Bi, Z.; Hou, B.; Cao, Y. Q.; Hu, Y. Y. Further treatment of decolorization liquid of azo dye coupled with increased power production using microbial fuel cell equipped with an aerobic biocathode. Water Res. 2011, 45 (1), 283-291.

(33) Huang, L. P.; Chai, X. L.; Chen, G. H.; Logan, B. E. Effect of set potential on hexavalent chromium reduction and electricity generation from biocathode microbial fuel cells. Environ. Sci. Technol. 2011, 45 (11), 5025-5031.

(34) Gregory, K. B.; Lovley, D. R. Remediation and recovery of uranium from contaminated subsurface environments with electrodes. Environ. Sci. Technol. 2005, 39 (22), 8943-8947.

(35) Thrash, J. C.; Van Trump, J. I.; Weber, K. A.; Miller, E.; Achenbach, L. A.; Coates, J. D. Electrochemical stimulation of microbial perchlorate reduction. Environ. Sci. Technol. 2007, 41 (5), $1740-1746$.

(36) Wang, A. J.; Cheng, H. Y.; Liang, B.; Ren, N. Q.; Cui, D.; Lin, N.; Kim, B. H.; Rabaey, K. Efficient reduction of nitrobenzene to aniline with a biocatalyzed cathode. Environ. Sci. Technol. 2011, 45 (23), 10186-10193.

(37) Mu, Y.; Rozendal, R. A.; Rabaey, K.; Keller, J. Nitrobenzene removal in bioelectrochemical systems. Environ. Sci. Technol. 2009, 43 (22), 8690-8695.

(38) Wang, A. J.; Cui, D.; Cheng, H. Y.; Guo, Y. Q.; Kong, F. Y.; Ren, N. Q; Wu, W. M. A membrane-free, continuously feeding, single chamber up-flow biocatalyzed electrolysis reactor for nitrobenzene reduction. J. Hazard. Mater. 2012, 199, 401-409.

(39) Harnisch, F.; Gimkiewicz, C.; Bogunovic, B.; Kreuzig, R.; Schröder, U. On the removal of sulfonamides using microbial bioelectrochemical systems. Electrochem. Commun. 2013, 26, 77-80.

(40) Wen, Q.; Kong, F. Y.; Zheng, H. T.; Yin, J. L.; Cao, D. X.; Ren, Y. M.; Wang, G. L. Simultaneous processes of electricity generation and ceftriaxone sodium degradation in an air-cathode single chamber microbial fuel cell. J. Power Sources 2011, 196 (5), 2567-2572.

(41) Wen, Q.; Kong, F. Y.; Zheng, H. T.; Cao, D. X.; Ren, Y. M.; Yin, J. L. Electricity generation from synthetic penicillin wastewater in an air-cathode single chamber microbial fuel cell. Chem. Eng. J. 2011, 168 (2), 572-576.

(42) Liang, B.; Yang, C.; Gong, M.; Zhao, Y.; Zhang, J.; Zhu, C.; Jiang, J.; Li, S. Adsorption and degradation of triazophos, chlorpyrifos and their main hydrolytic metabolites in paddy soil from Chaohu Lake, China. J. Environ. Manage. 2011, 92 (9), 2229-2234.

(43) Ren, N. Q.; Xing, D. F.; Rittmann, B. E.; Zhao, L. H.; Xie, T. H.; Zhao, X. Microbial community structure of ethanol type fermentation in bio-hydrogen production. Environ. Microbiol. 2007, 9 (5), 11121125.

(44) Shaw, W. V.; Leslie, A. G. W. Chloramphenicol acetyltransferase. Annu. Rev. Biophys. Biophys. Chem. 1991, 20, 363-386.

(45) Aminov, R. I.; Mackie, R. I. Evolution and ecology of antibiotic resistance genes. FEMS Microbiol. Lett. 2007, 271 (2), 147-161.

(46) Gross, B. J.; Branchflower, R. V.; Burke, T. R.; Lees, D. E.; Pohl, L. R. Bone marrow toxicity in vitro of chloramphenicol and its metabolites. Toxicol. Appl. pharmacol. 1982, 64 (3), 557-565.

(47) Qu, Y.; Spain, J. C. Catabolic pathway for 2-nitroimidazole involves a novel nitrohydrolase that also confers drug resistance. Environ. Microbiol. 2011, 13 (4), 1010-1017.

(48) Liang, B.; Jiang, J.; Zhang, J.; Zhao, Y.; Li, S. Horizontal transfer of dehalogenase genes involved in the catalysis of chlorinated compounds: Evidence and ecological role. Crit. Rev. Microbiol. 2012, 38 (2), 95-110.
(49) Yang, B.; Yu, G.; Huang, J. Electrocatalytic hydrodechlorination of 2,4,5-trichlorobiphenyl on a palladium-modified nickel foam cathode. Environ. Sci. Technol. 2007, 41 (21), 7503-7508.

(50) Chuanuwatanakul, S.; Chailapakul, O.; Motomizu, S. Electrochemical analysis of chloramphenicol using boron-doped diamond electrode applied to a flow-injection system. Anal. Sci. 2008, 24 (4), 493-498.

(51) Li, Y. P.; Cao, H. B.; Liu, C. M.; Zhang, Y. Electrochemical reduction of nitrobenzene at carbon nanotube electrode. J. Hazard. Mater. 2007, 148 (1-2), 158-163.

(52) Logan, B. E.; Call, D.; Cheng, S.; Hamelers, H. V. M; Sleutels, T. H. J. A.; Jeremiasse, A. W.; Rozendal, R. A. Microbial electrolysis cells for high yield hydrogen gas production from organic matter. Environ. Sci. Technol. 2008, 42 (23), 8630-8640.

(53) Rahal, A. G.; L., A. M. Degradation of 2,4,6-Trinitrotoluene (TNT) by soil bacteria isolated from TNT contaminated soil. Aust. J. Basic Appl. Sci. 2011, 5 (2), 8-17.

(54) Roldán, M. D.; Pérez-Reinado, E.; Castillo, F.; Moreno-Vivián, C. Reduction of polynitroaromatic compounds: The bacterial nitroreductases. FEMS Microbiol. Rev. 2008, 32 (3), 474-500.

(55) Parot, S.; Nercessian, O.; Delia, M. L.; Achouak, W.; Bergel, A. Electrochemical checking of aerobic isolates from electrochemically active biofilms formed in compost. J. Appl. Microbiol. 2009, 106 (4), $1350-1359$.

(56) Cournet, A.; Delia, M. L.; Bergel, A.; Roques, C.; Berge, M. Electrochemical reduction of oxygen catalyzed by a wide range of bacteria including Gram-positive. Electrochem. Commun. 2010, 12 (4), 505-508.

(57) Su, W. T.; Zhang, L. X.; Li, D. P.; Zhan, G. Q.; Qian, J. W.; Tao, Y. Dissimilatory nitrate reduction by Pseudomonas alcaliphila with an electrode as the sole electron donor. Biotechnol. Bioeng. 2012, 109 (11), 2904-2910.

(58) Su, W. T.; Zhang, L. X.; Tao, Y.; Zhan, G. Q.; Li, D. X.; Li, D. P. Sulfate reduction with electrons directly derived from electrodes in bioelectrochemical systems. Electrochem. Commun. 2012, 22, 37-40.

(59) Pham, T. H.; Boon, N.; Aelterman, P.; Clauwaert, P.; De Schamphelaire, L.; Vanhaecke, L.; De Maeyer, K.; Hofte, M.; Verstraete, W.; Rabaey, K. Metabolites produced by Pseudomonas sp enable a Gram-positive bacterium to achieve extracellular electron transfer. Appl. Microbiol. Biotechnol. 2008, 77 (5), 1119-1129.

(60) Venkataraman, A.; Rosenbaum, M. A.; Perkins, S. D.; Werner, J. J.; Angenent, L. T. Metabolite-based mutualism between Pseudomonas aeruginosa PA14 and Enterobacter aerogenes enhances current generation in bioelectrochemical systems. Energy Environ. Sci. 2011, 4 (11), 4550-4559.

(61) Zhang, T.; Li, B. Occurrence, transformation, and fate of antibiotics in municipal wastewater treatment plants. Crit. Rev. Environ. Sci. Technol. 2011, 41 (11), 951-998.

(62) Slater, J. H.; Bull, A. T.; Hardman, D. J. Microbial dehalogenation. Biodegradation 1995, 6 (3), 181-189. 